\title{
Histological reclassification of parotid gland carcinomas: importance for clinicians
}

\author{
Dominik Stodulski $^{1} \cdot$ Hanna Majewska ${ }^{2} \cdot$ Alena Skálová $^{3} \cdot$ Bogusław Mikaszewski $^{1}$. \\ Wojciech Biernat ${ }^{2} \cdot$ Czesław Stankiewicz $^{1}$
}

Received: 25 August 2015/Accepted: 11 April 2016/Published online: 21 April 2016

(C) The Author(s) 2016. This article is published with open access at Springerlink.com

\begin{abstract}
Reassessment of histological specimens of salivary gland carcinomas is associated with a change of primary diagnosis in a significant number of patients. The authors evaluated the relation between reclassification/ verification of histological diagnosis and the clinical course of parotid gland carcinomas. Histological and immunohistochemical examinations of 111 specimens of parotid gland carcinomas operated on during the years 1992-2010 were revised and in some cases supplemented with cytogenetic tests (FISH), to verify the diagnosis and potentially reclassify the tumours. Analysis of the clinical documentation and follow-up data of patients whose diagnosis was changed was then carried out. The prognostic factors taken into account in the evaluation of the clinical course included the $\mathrm{T}$ and $\mathrm{N}$ stage, the tumour grade and the extent of resection. The primary diagnosis was changed on review in 28 patients $(25.2 \%)$. In 16 patients, the change involved a different histological type of cancer. In six cases, what was thought to be a primary salivary gland cancer was reclassified as a secondary tumour. In four other cases, the change was made from a malignant to a benign tumour and in one case to a non-neoplastic lesion (necrotizing sialometaplasia). Additionally, in two patients with carcinoma ex pleomorphic adenoma, the malignant component was found to be of in situ type. A potentially atypical
\end{abstract}

Dominik Stodulski

dstodulski@gumed.edu.pl

1 Department of Otolaryngology, Medical University of Gdańsk, Gdańsk, Poland

2 Department of Pathomorphology, Medical University of Gdańsk, Gdańsk, Poland

3 Department of Pathology, Charles University in Prague, Faculty of Medicine in Pilsen, Pilsen, Czech Republic clinical course was observed in 4 out of 28 patients whose diagnosis was changed. In the case of 2 patients, the course of disease was more aggressive (dissemination, death) than predicted and less aggressive in rest of the patients. Histological reclassification/verification of parotid gland carcinomas can explain the cause of an atypical clinical course in some patients and sometimes enables doctors to implement a change in therapy.

Keywords Parotid gland carcinoma $\cdot$ Histopathology · Revision · Clinical course

\section{Introduction}

Parotid gland carcinomas constitute a very heterogeneous group of cancers. Their diagnosis is made based on their morphological, cytological and biological (clinical) features [1].

Histological classification of salivary gland tumours by WHO undergoes constant changes. During the first edition dated 1972, 7 types of carcinomas were distinguished, in 1991 there were 18 of them and the currently binding edition from year 2005 lists as many as 24 types of carcinomas [2-4]. In future editions, the number of types of salivary gland carcinomas will probably increase. Introduction of new types of cancers is associated both with difficulties in qualifying them to previous categories based on their morphological features (histological) and the immunohistochemical phenotype, in specifying the criteria of diagnosis and in introducing new techniques (for example, genetic tests for confirmation of a given mutation) [5]. According to the literature, after a reassessment of histological specimens of salivary gland carcinomas, primary diagnosis may be changed in up to $1 / 3$ of patients 
$[6,7]$. Reclassification can involve diagnosis change not only from one type of cancer into another of the same or different grade but also from a primary to a secondary (metastasis) tumour or from a malignant to benign lesion [8]. The last two situations are especially associated with clinical implications due to a risk of overdiagnosis and overtreatment or underdiagnosis and an inadequate treatment. For this reason, the authors of this article have evaluated the relation between reclassification/verification of histological diagnosis and the clinical course of parotid gland carcinomas in a large case series.

\section{Materials and methods}

Histological and immunohistochemical reassessment of 111 specimens of parotid gland carcinomas from resections performed at the Department of Otolaryngology of Medical University of Gdańsk during the years 1992-2010 was conducted in the Department of Pathomorphology of the Medical University of Gdańsk, Poland, to verify the diagnosis and potentially reclassify the tumours. Concurrently, the same specimens were independently examined and analysed cytogenetically at the Department of Pathology of the Charles University in Prague, Faculty of Medicine in Pilsen, Czech Republic. In case of differences in the assessment of specimens between the two centres, the examination was repeated and a consensus diagnosis was established. Reclassification was carried out according to histological classification by WHO from year 2005 and with addition of some new histological types of salivary gland neoplasms described since then $[4,5,9]$. Diagnoses were changed retrospectively based on microscopic appearance as interpreted by a pathologist experienced in salivary gland neoplasms, and taking into consideration clinical/follow-up data, additional immunohistochemical (IHC) and cytogenetic tests such as fluorescent in situ hybridization (FISH). Specifically, FISH was used to confirm the presence of ETV6-NTRK3 translocations in cases of mammary analogue secretory carcinoma (MASC) and CTRC1-MAML2 and CTRC3-MAML2 translocations in mucoepidermoid carcinoma (MEC) using previously described methodology $[9,10]$. The prognostic factors taken into account in evaluation of the clinical course included the stage, grade and margins status. Clinical stage was based on TNM of 2009 [11].

\section{Results}

\section{Histological analysis}

The primary diagnosis was changed in 28 of the 111 patients $(25.2 \%)$. In 16 of those patients, the change involved reclassification of the salivary carcinoma from one type to another, and specifically, in 6 cases the change was to a new type of salivary gland carcinoma not recognized in the 2005 WHO classification-mammary analogue secretory carcinoma (MASC)—based on the presence of ETV6-NTRK3 translocation. In another four cases, diagnosis was changed to salivary duct carcinoma (SDC), supported by positive expression of HER-2 protein. Two additional patients originally diagnosed with carcinoma ex pleomorphic adenoma (CxPA) on review were found to have in situ carcinoma arising in pleomorphic adenoma (CxPA in situ). In six cases, primary cancer of salivary gland was reclassified as a secondary tumour (metastases from the kidney, breast or skin), while in four other cases the diagnosis of carcinoma was changed to a benign neoplasm (adenoma) and one case to a non-neoplastic lesion (necrotizing sialometaplasia). The 28 diagnostic changes are summarized in Table 1.

\section{Clinical analysis}

Table 2 presents clinical and histopathological data of patients, whose diagnoses were revised. A potentially atypical clinical course was observed in 4 out of 28 patients, whose diagnoses were changed. In 2 of those 4 patients (no. 25 and 26), the course of the neoplastic disease was more aggressive (generalized neoplastic disease and death) than would be predicted based on original histological diagnosis, low grade, stage, and completeness of surgical excision. In both cases, the parotid gland tumour turned out to be a metastatic lesion on review. In 2 other patients (no. 17 and 21), the situation was opposite-unexpected asymptomatic course lasting for many years after tumour resection with uncertain margin. In the first case, the lesion was rediagnosed as "in situ" carcinoma ex pleomorphic adenoma and in the second case, as a nonmalignant neoplasm (a rare variant of myoepithelioma).

\section{Discussion}

For many clinicians, a change of histological diagnosis represents a certain taboo. In our series, the primary histopathological diagnosis was changed in about a quarter of patients. We were able to find only a few other reports discussing this issue. Van der Wal et al. reassessed specimens of tumours of small salivary glands and of the parotid gland, which resulted in change of diagnosis in 29 and $11.7 \%$ of patients, respectively. In that series, histological verification and reclassification was based exclusively on a repeat microscopic examination of the specimens. It is worth to point out that after histological revision, the diagnosis of 7 adenomas was changed to carcinoma (total 
Table 1 Methods and basis for reclassification of 28 parotid gland carcinomas

\begin{tabular}{|c|c|c|c|c|}
\hline \multirow{2}{*}{$\begin{array}{l}\text { Patient } \\
\text { no }\end{array}$} & \multirow{2}{*}{$\begin{array}{l}\begin{array}{l}\text { Primary } \\
\text { diagnosis }\end{array} \\
\text { MEC }\end{array}$} & \multirow{2}{*}{$\begin{array}{l}\text { Revised diagnosis } \\
\text { MASC HG }\end{array}$} & \multicolumn{2}{|c|}{ Methods and basis for reclassification } \\
\hline & & & FISH & Translocation ETV6-NTRK3 \\
\hline 2 & ACa NOS & MASC HG & FISH & Translocation ETV6-NTRK3 \\
\hline 3 & ACa NOS & MASC LG & FISH & Translocation ETV6-NTRK3 \\
\hline 4 & $\mathrm{AcCC}$ & MASC LG & FISH & Translocation ETV6-NTRK3 \\
\hline 5 & $\mathrm{AcCC}$ & MASC LG & FISH & Translocation ETV6-NTRK3 \\
\hline 6 & Papillary CAC & MASC LG & FISH & Translocation ETV6-NTRK3 \\
\hline 7 & $\mathrm{UCa}$ & $\mathrm{NCa}$ & $\mathrm{IHC}$ & $\begin{array}{l}\text { Chromogranin }+, \text { CD56+, synaptophysin }+, \text { TTF1-, S100- } \\
\text { CK20-, CK7- }\end{array}$ \\
\hline 8 & SCC G2 & SDC & $\mathrm{IHC}$ & AR-, HER2+, CK7+, p63-, S100- \\
\hline 9 & CxPA & SDC & IHC & $\mathrm{AR}+(20 \%), \mathrm{HER} 2+, \mathrm{CK} 7+$ \\
\hline 10 & MEC HG & SDC & IHC & $\mathrm{AR}+, \mathrm{HER} 2+, \mathrm{CK} 7+, \mathrm{p} 63-, \mathrm{S} 100-, \mathrm{EMA}+$ \\
\hline 11 & MEC HG & SDC & $\mathrm{IHC}$ & $\mathrm{AR}-, \mathrm{HER} 2+, \mathrm{CK} 7+, \mathrm{p} 63-, \mathrm{S} 100-, \mathrm{EMA}+$ \\
\hline 12 & ACa NOS & $\mathrm{AcCC}$ & $\mathrm{IHC}$ & $\mathrm{CK} 8+, \mathrm{CK} 7-, \mathrm{PAS}+, \mathrm{DOG} 1+$ \\
\hline 13 & AdCC & $\mathrm{AcCC}$ & IHC & DOG1,+ PAS + \\
\hline 14 & MEC & EMCa LG & IHC & $\mathrm{P} 63+, \mathrm{CK} 7+, \mathrm{CK} 14+$, calponin focally + \\
\hline 15 & BCAca & EMCa LG & IHC & P63+, CK7+, CK14+, calponin + \\
\hline 16 & $\mathrm{AcCC}$ & EMCa LG & $\mathrm{IHC}$ & $\mathrm{P} 63+, \mathrm{CK} 7+, \mathrm{CK} 14+$, calponin + \\
\hline 17 & CxPA (SDC) & CXPA in situ & $\mathrm{H} \& \mathrm{E}$ & \\
\hline 18 & $\begin{array}{l}\text { CxPA }(\mathrm{ACa} \\
\text { NOS) }\end{array}$ & CXPA in situ & $\mathrm{H} \& \mathrm{E}$ & \\
\hline 19 & CxPA & PA with SCM & $\mathrm{H} \& \mathrm{E}$ & Lack of atypia \\
\hline 20 & MEC & PA with SCM & H\&E/FISH & Lack of translocation CTRC1-MAML2/CTRC3-MAML2 \\
\hline 21 & Clear cell $\mathrm{Ca}$ & $\begin{array}{l}\text { Myoepithelioma (clear cell } \\
\text { variant) }\end{array}$ & $\mathrm{IHC}$ & S100+, SMA+, calponin,+ GFAP + \\
\hline 22 & MEC & Metaplastic WT & H\&E/FISH & Lack of translocation CTRC1-MAML2/CTRC3-MAML2 \\
\hline 23 & PLGA & Necrotizing sialometaplasia & $\mathrm{H} \& \mathrm{E}$ & \\
\hline 24 & MEC & SCC metastases (skin) & $\begin{array}{l}\text { H\&E/clinical } \\
\text { data/follow-up }\end{array}$ & PAS - , mucicarmine- \\
\hline 25 & Clear cell $\mathrm{Ca}$ & RCC metastases & $\begin{array}{l}\text { IHC/clinical } \\
\text { data/follow-up }\end{array}$ & $\mathrm{CD} 10+, \mathrm{RCC}+$ \\
\hline 26 & $\mathrm{AcCC}$ & RCC metastases & $\begin{array}{l}\text { IHC/clinical } \\
\text { data/follow-up }\end{array}$ & $\mathrm{CD} 10+, \mathrm{RCC}+$ \\
\hline 27 & $\mathrm{AcCC}$ & RCC metastases & $\begin{array}{l}\text { IHC/clinical } \\
\text { data/follow-up }\end{array}$ & $\mathrm{CD} 10+, \mathrm{RCC}+$ \\
\hline 28 & $\mathrm{AcCC}$ & $\mathrm{BC}$ metastases & $\begin{array}{l}\text { IHC/clinical } \\
\text { data/follow-up }\end{array}$ & Mammaglobin + \\
\hline
\end{tabular}

MASC mammary analogue secretory carcinoma, SDC salivary duct carcinoma, ACA NOS adenocarcinoma not otherwise specified, $C x P A$ carcinoma ex pleomorphic adenoma, $M E C$ mucoepidermoid carcinoma, SCC squamous cell carcinoma, AcCC acinic cell carcinoma, AdCC adenoid cystic carcinoma, EMCa epithelial-myoepithelial carcinoma, UCa undifferentiated carcinoma, PLGA polymorphous low-grade adenocarcinoma, $N C a$ neuroendocrine carcinoma, $C A C$ cystadenocarcinoma, $R C C$ renal cell carcinoma, $B C$ breast carcinoma, $W T$ Warthin tumour, $P A$ pleomorphic adenoma, $S C M$ squamous cell metaplasia, $H G$ high grade, $I G$ intermediate grade, $L G$ low grade, $H \& E$ hematoxylin and eosin, IHC immunohistochemistry

in intraoral and parotid location): (2 polymorphous lowgrade adenocarcinoma, 2 MEC, adenoid cystic carcinoma, epithelial-myoepithelial carcinoma, malignant myoepithelioma), and 6 cancers (2 MEC, 2 adenoid cystic carcinoma, CXPA, adenocarcinoma not otherwise specified) to adenomas and cyst $[6,7]$. In the study presented by Godballe et al., in which 85 parotid gland carcinomas were reanalysed, diagnosis was changed after microscopic reassessment and immunohistochemical tests in 20 patients (23.5\%) [8]. In a large national study in Denmark, a revision of 886 cancers of the large and small salivary glands was done and diagnosis was changed in 121 of them $(14 \%)$. In 11 cases, the diagnosis was changed from carcinoma to adenoma, in $7 \mathrm{CxPA}$ in situ was diagnosed, and 
Table 2 Clinical course and follow-up of patients with revised diagnosis

\begin{tabular}{|c|c|c|c|c|c|c|c|c|}
\hline No & Age & Sex & Primary histology & Grade & TNM & Resection & Revised histology & Status/years \\
\hline 1 & 60 & M & MEC & IG & pT4aN1 & $\mathrm{R} 1+\mathrm{RT}$ & MASC HG & DOD/1 \\
\hline 2 & 73 & M & ACa NOS & HG & pT3N0 & $\mathrm{R} 1+\mathrm{RT}$ & MASC HG & $\mathrm{L} / \mathrm{NR} / 2,3,4$ \\
\hline 3 & 63 & M & ACa NOS & LG & pT3N0 & $\mathrm{R} 1+\mathrm{RT}$ & MASC LG & $\mathrm{NED} / 9$ \\
\hline 4 & 51 & $\mathrm{~K}$ & $\mathrm{AcCC}$ & LG & pT2N0 & R0 & MASC LG & $\mathrm{NED} / 7$ \\
\hline 5 & 75 & $\mathrm{~K}$ & $\mathrm{AcCC}$ & LG & pT3N0 & $\mathrm{R} 1$ & MASC LG & $\mathrm{NED} / 5$ \\
\hline 6 & 42 & $\mathrm{~K}$ & Papillary CAC & LG & pT2N0 & R0 & MASC LG & $\mathrm{NED} / 9$ \\
\hline 7 & 46 & $\mathrm{~K}$ & $\mathrm{UCa}$ & IG & pT2N0 & R0 & $\mathrm{NCa} \mathrm{IG}$ & $\mathrm{NED} / 20$ \\
\hline 8 & 71 & $\mathrm{~K}$ & SCC & HG & $\mathrm{pT} 3 \mathrm{~N} 2 \mathrm{~b}$ & $\mathrm{Rx}+\mathrm{RT}$ & SDC HG & $\mathrm{DOD} / 3$ \\
\hline 9 & 57 & M & CxPA & HG & pT4aN1 & $\mathrm{R} 1+\mathrm{RT}$ & SDC HG & $\mathrm{DOD} / 1$ \\
\hline 10 & 67 & M & MEC & HG & $\mathrm{pT} 4 \mathrm{aN} 2 \mathrm{~b}$ & $\mathrm{R} 1+\mathrm{RT}$ & SDC HG & $\mathrm{DOD} / 2$ \\
\hline 11 & 47 & $\mathrm{~K}$ & MEC & $\mathrm{HG}$ & pT4aN2b & $\mathrm{Rx}+\mathrm{RT}$ & SDC HG & NED/20 \\
\hline 12 & 48 & $\mathrm{~K}$ & ACa NOS & IG & pT2N0 & R0 & AcCC LG & NED/19 \\
\hline 13 & 62 & M & AdCC & $\mathrm{HG}$ & pT2N0 & R0 & AcCC HG & $\mathrm{LNR} / 3$ \\
\hline 14 & 75 & M & MEC & IG & pT2N0 & R0 & EMCa LG & $\mathrm{NED} / 6$ \\
\hline 15 & 52 & $\mathrm{~K}$ & BCAca & LG & pT2N0 & $\mathrm{R} 1+\mathrm{RT}$ & EMCa LG & $\mathrm{LR} / 2,4,9$ \\
\hline 16 & 67 & M & $\mathrm{AcCC}$ & LG & pT2N0 & R0 & EMCa LG & NED/15 \\
\hline 17 & 42 & M & CxPA (SDC) & HG & pT3N0 & $\mathrm{Rx}$ & CxPA in situ & NED/15 \\
\hline 18 & 51 & M & CxPA (ACa NOS) & HG & pT2N0 & R0 & CxPA in situ & $\mathrm{NED} / 9$ \\
\hline 19 & 40 & $\mathrm{~K}$ & CxPA (ACa NOS) & & pT2N0 & R0 & PA with SCM & NED/17 \\
\hline 20 & 71 & $\mathrm{~K}$ & MEC & IG & pT2N0 & R0 & PA with SCM & $\mathrm{DOC} / 10$ \\
\hline 21 & 42 & $\mathrm{~K}$ & Clear cell $\mathrm{Ca}$ & LG & pT2N0 & $\mathrm{Rx}$ & Myoepithelioma & $\mathrm{NED} / 9$ \\
\hline 22 & 56 & M & MEC & LG & pT2N0 & R0 & Metaplastic WT & $\mathrm{NED} / 9$ \\
\hline 23 & 35 & $\mathrm{~K}$ & PLGA & LG & pT2N0 & $\mathrm{R} 1$ & Necrotizing sialometaplasia & $\mathrm{NED} / 5$ \\
\hline 24 & 70 & M & MEC & & pT2N1 & R0; RT & SCC metastases (skin) & $\mathrm{NED} / 6$ \\
\hline 25 & 68 & M & Clear cell $\mathrm{Ca}$ & LG & pT2N0 & R0 & RCC metastases & $\mathrm{DOD} / 2$ \\
\hline 26 & 65 & $\mathrm{~K}$ & $\mathrm{AcCC}$ & LG & pT1N0 & R0 & RCC metastases & $\mathrm{DOD} / 2$ \\
\hline 27 & 76 & $\mathrm{~K}$ & $\mathrm{AcCC}$ & LG & pT2N0 & $\mathrm{Rx}$ & RCC metastases & AWD/4 \\
\hline 28 & 75 & $\mathrm{~K}$ & $\mathrm{AcCC}$ & LG & pT1N0 & R0 & BC metastases & NED/10 \\
\hline
\end{tabular}

MASC mammary analogue secretory carcinoma, $S D C$ salivary duct carcinoma, $A C A N O S$ adenocarcinoma not otherwise specified, $C x P A$ carcinoma ex pleomorphic adenoma, $M E C$ mucoepidermoid carcinoma, SCC squamous cell carcinoma, AcCC acinic cell carcinoma, AdCC adenoid cystic carcinoma, EMCa epithelial-myoepithelial carcinoma, UCa undifferentiated carcinoma, PLGA polymorphous low-grade adenocarcinoma, $N C a$ neuroendocrine carcinoma, $C A C$ cystadenocarcinoma, $R C C$ renal cell carcinoma, $B C$ breast carcinoma, WT Warthin tumour, $P A$ pleomorphic adenoma, $S C M$ squamous cell metaplasia, $H G$ high grade, $I G$ intermediate grade, $L G$ low grade, $A W D$ alive with disease, $N E D$ no evidence of disease, $D O D$ died of disease, $D O C$ died of other cause, $L R$ local recurrence, $N R$ nodal recurrence, $R T$ radiation therapy, $R I$ microscopically positive margin, $R x$ microscopically uncertain margin, $R O$ microscopically negative margin

in next 12 cases cancers appeared to be non-epithelial malignant tumours, and in 90 cases a subtype of cancer was changed. In one case, it was found that the cancer does not originate from the salivary glands [12]. Histological assessment of salivary gland neoplasms is difficult and requires specialist experience to avoid diagnostic traps, such as misdiagnosis of necrotizing sialometaplasia or squamous metaplasia within Warthin tumour as carcinoma $[10,12,13]$. Moreover, due to significant progress in the adjunct diagnostic procedures, diagnosis of parotid gland carcinomas may require immunohistochemical and molecular tests. Nowadays, many types of cancers of the salivary glands (adenoid cystic carcinoma, epithelial- myoepithelial carcinoma, MEC, MASC, hyalinizing clear cell carcinoma, CXPA, SDC, acinic cell carcinoma) have specific molecular biomarkers, which are used to confirm the diagnosis and also have prognostic significance [14]. Interesting results were presented by Bishop et al. After microscopic and immunohistochemical re-evaluation, and after applying molecular techniques (FISH) to acinic cell carcinoma (AcCC) specimens, the diagnosis was changed to an MASC in $9 / 11$ ( $82 \%$ ) of tumours in intraoral location, $2 / 2$ in submandibular gland, and only in 3 of 16 $(19 \%)$ in parotid [15]. Another problem faced by nonspecialist pathologists is lack of awareness of newly defined salivary neoplasms such as mucinous variant of 
myoepithelioma and MASC, as discovered in our study. This is illustrated in our study by the relatively high number of patients, whose diagnoses were changed from primary carcinoma of a salivary gland to a secondary lesion (metastasis to the parotid gland from kidneys, breast or skin). This is similar to the findings of Godballe et al., who reported revision of primary carcinomas to metastatic ones in $6 \%$ of patients, with the primary location of the tumour in the breast, prostate, skin and lung [8]. Metastases to the parotid gland make $5-11 \%$ of all malignancies of this gland with the vast majority of them originating in the skin on the head (squamous cell carcinoma and malignant melanoma) [16-18]. However, occasionally, the primary malignancy is located outside the head and neck (kidney, breast and lung), and the metastatic tumour can be its first symptoms [18, 19]. This illustrates why access to full clinical data is necessary for proper diagnosis [16-19].

Predicting the clinical course based on histology and progression of the disease is not obvious and to a great extent is subjective. In the studies by Van der Wal et al., during further follow-up of patients after histological reclassification there were no events observed to confirm the accuracy of diagnosis change [6,7]. A change in the diagnosis from a malignant neoplasm to a benign one, a non-neoplastic lesion or an in situ cancer (CXPA), has a psychological significance for the patient; however, the practical (economic) aspect is important as well (shortening/conclusion of follow-up). Moreover, a change in diagnosis can occasionally enable new therapeutic options such as use of monoclonal antibody treatment (Trastuzumab, Cetuximab), kinases inhibitors BRAF, MTOR, MEK, androgen receptor blockers and others [14, 20].

\section{Conclusions}

Histological assessment of salivary gland carcinomas should be carried out by an experienced pathologist with an access to a specific panel of IHC and molecular tests. It is also crucial for pathologists to have access to patients' full clinical data, especially the information about past treatment of other primary neoplasms. Histological reclassification/verification of parotid gland carcinomas can help explain the cause of atypical clinical course in some patients, and may sometimes enable clinicians to implement proper therapy at early stages of the disease.

\section{Compliance with ethical standards}

Competing interests None declared.

Funding None.
Open Access This article is distributed under the terms of the Creative Commons Attribution 4.0 International License (http://crea tivecommons.org/licenses/by/4.0/), which permits unrestricted use, distribution, and reproduction in any medium, provided you give appropriate credit to the original author(s) and the source, provide a link to the Creative Commons license, and indicate if changes were made.

\section{References}

1. Luna MA (2000) Salivary glands. In: Pilch BZ (ed) Head and neck surgical pathology. Lippincott Williams \& Wilkins, Philadelphia

2. Thackray AC, Sobin LH (1972) Histological typing of salivary gland tumours. World Health Organization. International classification of tumours. The organization, Geneva

3. Seifert G, Sobin LH (1991) Histological typing of salivary gland tumours. World Health Organization. International classification of tumours. Springer, Berlin

4. Barnes L, Eveson JW, Reichart P, Sidransky D (2005) World Health Organization classification of tumours. Pathology and genetics of head and neck tumours. IARC, Lyon

5. Gnepp DR (2014) Salivary gland tumor "wishes" to add to the next WHO tumor classification: sclerosing polycystic adenosis, mammary analogue secretory carcinoma, cribriform adenocarcinoma of the tongue and other sites, and mucinous variant of myoepithelioma. Head Neck Pathol 8:42-49

6. van der Wal JE, Snow GB, van der Waal I (1992) Histological reclassification of 101 intraoral salivary gland tumours (new WHO classification). J Clin Pathol 45:834-835

7. van der Wal JE, Leverstein H, Snow GB, Kraaijenhagen HA, van der Waal I (1998) Parotid gland tumors: histologic reevaluation and reclassification of 478 cases. Head Neck 20:204-207

8. Godballe C, Schultz JH, Krogdahl A, Møller-Grøntved A, Johansen J (2003) Parotid carcinoma: impact of clinical factors on prognosis in a histologically revised series. Laryngoscope 113:1411-1417

9. Majewska H, Skálová A, Stodulski D, Klimková A, Steiner P, Stankiewicz C, Biernat W (2015) Mammary analogue secretory carcinoma of salivary glands: a new entity associated with ETV6 gene rearrangement. Virchows Arch 466:245-254

10. Skálová A, Vanecek T, Simpson RH, Vazmitsel MA, Majewska H, Mukensnabl P, Hauer L, Andrle P, Hosticka L, Grossmann P, Michal M (2013) CRTC1-MAML2 and CRTC3-MAML2 fusions were not detected in metaplastic Warthin tumor and metaplastic pleomorphic adenoma of salivary glands. Am J Surg Pathol 37:1743-1750

11. Wittekind C, Meyer HJ (2009) Head neck cancer. In: Sobin LH, Gospodarowicz MK, Wittekind C (eds) UICC TNM classification of malignant tumours, 7th edn. Wiley, New York, pp 23-60

12. Bjørndal K, Krogdahl A, Therkildsen MH, Overgaard J, Johansen J, Kristensen CA, Homøe P, Sørensen CH, Andersen E, Bundgaard T, Primdahl H, Lambertsen K, Andersen LJ, Godballe C (2011) Salivary gland carcinoma in Denmark 1990-2005: a national study of incidence, site and histology. Results of the Danish Head and Neck Cancer Group (DAHANCA). Oral Oncol 47:677-682

13. Carlson DL (2009) Necrotizing sialometaplasia: a practical approach to the diagnosis. Arch Pathol Lab Med 133:692-698

14. Stenman G, Persson F, Andersson MK (2014) Diagnostic and therapeutic implications of new molecular biomarkers in salivary gland cancers. Oral Oncol 50:683-690

Ethical approval Not required. 
15. Bishop JA, Yonescu R, Batista D, Eisele DW, Westra WH (2013) Most nonparotid "acinic cell carcinomas" represent mammary analog secretory carcinomas. Am J Surg Pathol 37:1053-1057

16. Löning T, Jäkel KT (2005) Secondary tumours. In: Barnes L, Eveson JW, Reichart P, Sidransky D (eds) World Health Organization classification of tumours. Pathology and genetics of head and neck tumours. IARC, Lyon, p 281

17. Kopeć T, Mikaszewski B, Jackowska J, Waśniewska-Okupniak E, Szyfter W, Wierzbicka M (2015) Treatment of parotid malignancies - 10 years of experience. J Oral Maxillofac Surg 73:1397-1402
18. Nuyens M, Schüpbach J, Stauffer E, Zbären P (2006) Metastatic disease to the parotid gland. Otolaryngol Head Neck Surg 135:844-848

19. Mrena R, Leivo I, Passador-Santos F, Hagström J, Mäkitie AA (2008) Histopathological findings in parotid gland metastases from renal cell carcinoma. Eur Arch Otorhinolaryngol 265:1005-1009

20. Lee JS, Kwon OJ, Park JJ, Seo JH (2014) Salivary duct carcinoma of the parotid gland: is adjuvant HER-2-targeted therapy required? J Oral Maxillofac Surg 72:1023-1031 